\title{
Magnetic field control of microstructural development in melt-spun $\operatorname{Pr}_{2} \mathrm{Co}_{14} B$
}

\author{
Michael A. McGuire, ${ }^{*}$ Orlando Rios, Ben S. Conner, and William G. Carter \\ Oak Ridge National Laboratory, Oak Ridge, Tennessee, USA \\ Mianliang Huang, Kewei Sun, Olena Palasyuk, Brandt Jensen, Lin \\ Zhou, Kevin Dennis, Ikenna C. Nlebedim, and Matthew J. Kramer \\ The Ames Laboratory, Ames, Iowa, USA
}

\begin{abstract}
In the processing of commercial rare earth permanent magnets, use of external magnetic fields is limited mainly to the alignment of anisotropic particles and the polarization of the finished magnets. Here we explore the effects of high magnetic fields on earlier stages of magnet synthesis, including the crystallization and chemical phase transformations that produce the $2: 14: 1$ phase in the $\mathrm{Pr}-\mathrm{Co}-\mathrm{B}$ system. $\operatorname{Pr}_{2} \mathrm{Co}_{14} \mathrm{~B}$ alloys produced by melt-spinning were annealed in the presence of strong applied magnetic fields $(\mathrm{H}=90 \mathrm{kOe})$. The resulting materials were characterized by x-ray diffraction, electron microscopy, and magnetization measurements. We find that magnetic fields suppress the nucleation and growth of crystalline phases, resulting in significantly smaller particle sizes. In addition, magnetic fields applied during processing strongly affects chemical phase selection, suppressing the formation of $\operatorname{Pr}_{2} \mathrm{Co}_{14} \mathrm{~B}$ and $\alpha$-Co in favor of $\operatorname{Pr}_{2} \mathrm{Co}_{17}$. The results demonstrate that increased control over key microstructural properties is achievable by including a strong magnetic field as a processing parameter for rare-earth magnet materials.
\end{abstract}

\section{INTRODUCTION}

Applied magnetic fields play important roles in the manufacturing of permanent magnet materials. The simplest application is the magnetization of the finished part, but magnetic fields are also used for crystallographic alignment in almost all anisotropic magnets (the exception being die-upset magnets) [1]. In anisotropic rare earth magnets the field is used to align free-flowing particles before the materials are sintered [1], while in AlNiCo the field is used to induce anisotropic precipitation and growth of the $\mathrm{Fe} / \mathrm{Co}$-rich magnetic phase [2, 3]. Large magnetic fields can have other thermodynamic consequences when applied to strongly magnetic materials. One example can be seen in $\mathrm{MnBi}$, a permanent magnet material that decomposes near $630 \mathrm{~K}$ into non-ferromagnetic phases $\mathrm{Mn}_{1+x} \mathrm{Bi}$ and $\mathrm{Bi}$ [4]. Application of a magnetic field can stabilize the ferromagnetic $\mathrm{MnBi}$ phase to higher temperature, pushing the decomposition temperature up at a rate of about 2 $\mathrm{K} / \mathrm{T}[5,6]$. The effects of large magnetic fields on materials at elevated temperature, especially near phase transformations, can be significant for both magnetic and non-magnetic materials. For example, crystallographic texture can be produced even in non-magnetic polymer materials [7].

Several studies of the effects of high magnetic fields during the thermal processing of rare-earth magnet materials

\footnotetext{
*McGuireMA@ornl.gov

Notice: This manuscript has been authored by UT-Battelle, LLC under Contract No. DE-AC05-00OR22725 with the U.S. Department of Energy. The United States Government retains and the publisher, by accepting the article for publication, acknowledges that the United States Government retains a non-exclusive, paid-up, irrevocable, world-wide license to publish or reproduce the published form of this manuscript, or allow others to do so, for United States Government purposes. The Department of Energy will provide public access to these results of federally sponsored research in accordance with the DOE Public Access Plan(http://energy.gov/downloads/doe-public-access-plan).
}

can be found in the literature [8], primarily concerning $\mathrm{Nd}_{2} \mathrm{Fe}_{14} \mathrm{~B}$-based alloys. These include studies of solidification $[9,10]$ and nucleation [11], as well as effects on composite magnets [12], sintered magnets [13], and powders produced by the hydrogenation-disproportionation-desorptionrecombination process [14]. Kato et al. crystallized nanocomposite ribbons of Nd-Co-B under high magnetic fields and found a significant increase in coercivity as well as a small amount of crystallographic texture [15]. $\operatorname{Pr}_{2} \mathrm{Co}_{14} \mathrm{~B}$, with a Curie temperature near $1000 \mathrm{~K}$ and anisotropy field of 100 $\mathrm{kOe}$ at room temperature, has received some attention as a potential high temperature magnet material [16-21]. Otani et al. examined the effect of a relatively low magnetic field $(3 \mathrm{kOe})$ during the crystallization of $\operatorname{Pr}_{2} \mathrm{Co}_{14} \mathrm{~B}$ and found that the resulting texture was enhanced relative to materials crystallized with no applied magnetic field [22].

In this work we have examined the effects of high magnetic fields on the microstructural development of rapidly quenched $\mathrm{Pr}_{2} \mathrm{Co}_{14} \mathrm{~B}$-based materials produced by melt-spinning. The as-spun material was heat treated for a short time at temperatures ranging from 450 to $730^{\circ} \mathrm{C}$ in applied magnetic fields of $\mathrm{H}=0-90 \mathrm{kOe}$. X-ray diffraction (XRD) and transmission electron microscopy (TEM) were used to monitor the microstructural development. Strong effects of the magnetic field were observed, including a suppression of grain size developed at lower temperatures and a suppression of the transformation of $\mathrm{Pr}_{2} \mathrm{Co}_{17}$ to $\mathrm{Pr}_{2} \mathrm{Co}_{14} \mathrm{~B}$ at higher temperatures. This work demonstrates the potential of high magnetic field processing to achieve enhanced microstructural control in rare-earth magnet materials.

\section{EXPERIMENTAL}

Ingots with composition $\operatorname{Pr}_{2} \mathrm{Co}_{14} \mathrm{~B}$ were prepared by arc melting in Ar atmosphere. Melt spun ribbons were prepared by inductively melting the ingots in quartz crucibles and eject- 
ing the melt onto a single $\mathrm{Cu}$ wheel at $30 \mathrm{~m} / \mathrm{s}$ surface velocity through a $0.8 \mathrm{~mm}$ orifice. Melt spinning was performed in $1 / 3$ atmosphere of high purity $\mathrm{He}$ gas. Both the as-spun ribbon and powders derived from grinding the ribbons were used for $\mathrm{x}$-ray diffraction (XRD) with $\mathrm{Co} \mathrm{K} \alpha$ radiation. Simultaneous thermogravimetry and differential scanning calorimetry analysis (TG/DSC) were performed at a heating rate of $20^{\circ} \mathrm{C} / \mathrm{min}$. Two permanent magnets attached to the measurement system create a magnetic field gradient on the sample. As a result, apparent mass changes are observed at Curie and spin reorientation temperatures. Changes in permeability due to changes in magnetocrystalline anisotropy with temperature are also detected [21].

For heat treatments, ribbon segments were wrapped in $\mathrm{Ta}$ foil and sealed inside silica ampoules that had been evacuated and back-filled with $1 / 3$ of an atmosphere of ultra-high purity argon. Thermocouples were attached to the surface of the ampoules and used for controlling the temperature. Radio frequency induction heating was used to heat a graphite susceptor surrounding the ampoules inside the bore of a 9 Tesla superconducting magnet [23]. The magnetic field was applied along the long axis of the ribbon samples. X-ray diffraction of the heat treated samples was performed with a PANalytical X'Pert Pro MPD diffractometer using $\mathrm{Cu}-\mathrm{K}_{\alpha 1}$ radiation. Diffraction patterns were collected from the surfaces of the processed ribbons. An FEI Tecnai G2 F20 transmission electron microscope (TEM) with energy dispersive $\mathrm{x}$-ray (EDX) detector was used for microstructural characterization. TEM specimens were made using wedge polishing technique followed by Ar ion milling with liquid nitrogen cooling. Magnetic hysteresis loops were measured on the isotropic ribbons at $300 \mathrm{~K}$ in a vibrating sample magnetometer up to a maximum applied field of $30 \mathrm{kOe}$.

\section{RESULTS}

The cobalt rich portion of the Pr-Co-B phase diagram contains at least 11 ternary phases [24], so complex alloys and microstructural evolution may be expected in this system. XRD from the surface of the as-spun $\operatorname{Pr}_{2} \mathrm{Co}_{14} \mathrm{~B}$ sample used in the present study showed only $\mathrm{Pr}_{2} \mathrm{Co}_{17}$, while data from ground powders revealed the presence of some $\operatorname{Pr}_{2} \mathrm{Co}_{14} \mathrm{~B}$ in the interior of the ribbons (Figure 1a). The measured relative intensities of the Bragg peaks in the powdered sample are in reasonable agreement with the calculated patterns. The peak intensities from the surface of the ribbon show some discrepancy with the reference patterns. Notably the main reflections, 220 and 033 near $50^{\circ}$ have anomalously large intensity. The indices of these two reflections do not suggest any simple preferential orientation or texture is responsible, and the result may be due to incomplete powder-averaging in this measurement from the as-spun ribbon surface.

Results of TG measurements in a small magnetic field gradient are shown in Figure 1b. Sharp changes in the magnetic permeability of the sample are seen upon heating at about 390 , 720 , and $1120^{\circ} \mathrm{C}$. These are associated with the spin reorientation in $\mathrm{Pr}_{2} \mathrm{Co}_{14} \mathrm{~B}\left(390^{\circ} \mathrm{C}\right)$, the Curie temperature of $\mathrm{Pr}_{2} \mathrm{Co}_{14} \mathrm{~B}$ $\left(720^{\circ} \mathrm{C}\right)$, and the Curie temperature of $\operatorname{Co}\left(1130^{\circ} \mathrm{C}\right)$. The absence of a signature near the Curie temperature of $\mathrm{Pr}_{2} \mathrm{Co}_{17}$ $\left(898^{\circ} \mathrm{C}\right)$ indicates that this phase, the predominant phase in the as spun material, is completely transformed to $\mathrm{Pr}_{2} \mathrm{Co}_{14} \mathrm{~B}$ at temperatures below $900^{\circ} \mathrm{C}$. Calorimetry data shown in Figure $1 \mathrm{~b}$ shows broad thermal signatures between about 400 and $800^{\circ} \mathrm{C}$, presumably related to chemical phase transformations, and sharper features at higher temperature associated with the decomposition of $\mathrm{Pr}_{2} \mathrm{Co}_{14} \mathrm{~B}[21,25]$. Based on the TG/DSC results, processing temperatures of $450,550,650$, and $730^{\circ} \mathrm{C}$ were selected. Temperature profiles used for the processing experiments are shown in Figure 1c. Samples were heated at the same rate as that used in the thermal analysis measurements, held for 3 minutes at the target temperatures, and then rapidly cooled. Cooling to $200^{\circ} \mathrm{C}$ occurred over $2-3$ minutes. These heat treatments were done in applied fields of zero and $90 \mathrm{kOe}$.

Results of XRD measurements from the surfaces of thermally treated ribbons are summarized in Figure 2. Reference patterns for the three phases of primary interest, $\alpha$-Co (fcc high temperature phase), $\mathrm{Pr}_{2} \mathrm{Co}_{14} \mathrm{~B}$, and $\mathrm{Pr}_{2} \mathrm{Co}_{17}$ are shown at the bottoms of panels $\mathrm{a}$ and $\mathrm{b}$. The thermal evolution at zero magnetic field (Figure 2a) can be described as follows. At $450^{\circ} \mathrm{C}$ the diffraction pattern looks much like that measured on the as spun ribbon (Figure 1a), with the exception of a broad peak near 41 degrees that may indicate the formation of $\mathrm{PrCo}_{2}$. At $550^{\circ} \mathrm{C}$ a significant amount of $\alpha$-Co has formed. At $650^{\circ} \mathrm{C}$ and $730^{\circ} \mathrm{C}$ the primary phases are $\alpha$-Co and $\operatorname{Pr}_{2} \mathrm{Co}_{14} \mathrm{~B}$. This shows that the transformation of $\operatorname{Pr}_{2} \mathrm{Co}_{17}$ to $\mathrm{Pr}_{2} \mathrm{Co}_{14} \mathrm{~B}$ occurs between 550 and $650^{\circ} \mathrm{C}$ in zero magnetic field.

The microstructural evolution is significantly different when the heat treatments are performed in an applied field of $90 \mathrm{kOe}$ (Figure 2b). At 450, 550, and $650^{\circ} \mathrm{C}, \mathrm{Pr}_{2} \mathrm{Co}_{17}$ is the primary phase, with crystallinity improving with increasing temperature. A large $\mathrm{Pr}_{2} \mathrm{Co}_{17}$ component remains even at $730^{\circ} \mathrm{C}$, coexisting with a significant fraction of $\alpha$-Co and a small amount of $\operatorname{Pr}_{2} \mathrm{Co}_{14} \mathrm{~B}$. The strong effect of the magnetic field at $650^{\circ} \mathrm{C}$ is more easily seen by the comparison shown in Figure 2c. The diffraction data in Figure 2a,b clearly show that applied magnetic field has a strong effect on chemical phase selection, suppressing the formation of both $\alpha$-Co and $\mathrm{Pr}_{2} \mathrm{Co}_{14} \mathrm{~B}$ in favor of $\mathrm{Pr}_{2} \mathrm{Co}_{17}$. In similar experiments on Nd-Co-B nanocomposite ribbons, a $100 \mathrm{kOe}$ field was shown to significantly increase the $\mathrm{Nd}_{2} \mathrm{Co}_{17}$ content relative to $\mathrm{Nd}_{2} \mathrm{Co}_{14} \mathrm{~B}$ when heating at $725^{\circ} \mathrm{C}$, but not at higher or lower temperatures [15]. A general suppression of elemental Co formation was also seen in that study.

The magnetic field applied during thermal processing is also observed to have a strong effect on the sharpness of the diffraction peaks. This is demonstrated by the comparison shown in Figure 2d. The relative broadening and shifting of the reflections in the $90 \mathrm{kOe}$ sample suggest that the magnetic field results in reduced crystallite size and perhaps increased strain.

Note that the apparently large Co component in some of the diffraction patterns suggests that Co may be preferentially forming at the surface of the ribbons. 

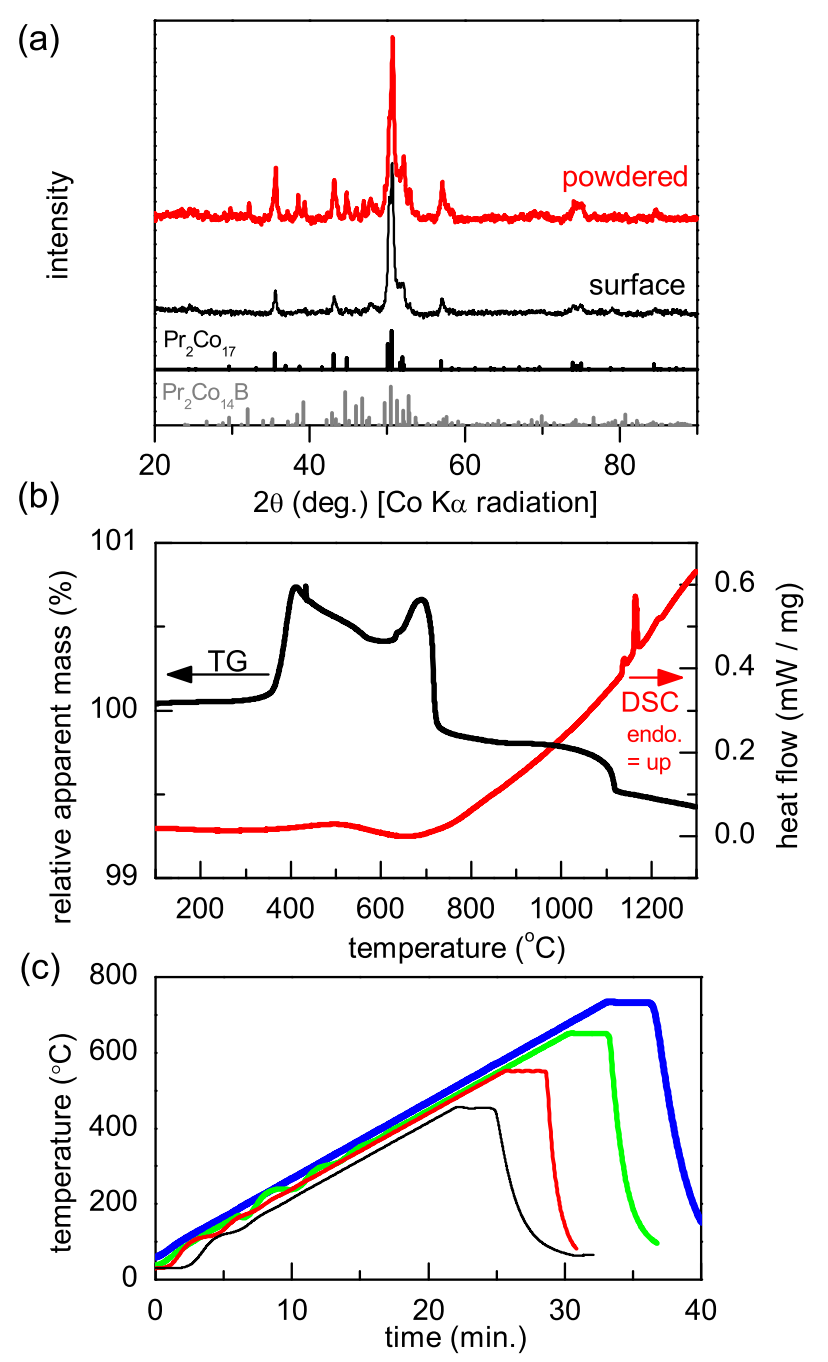

FIG. 1. (a) XRD patterns from the surface of the as spun $\operatorname{Pr}_{2} \mathrm{Co}_{14} \mathrm{~B}$ ribbons and from powder ground from the as spun ribbons. Reference patterns for $\operatorname{Pr}_{2} \mathrm{Co}_{17}$ and $\operatorname{Pr}_{2} \mathrm{Co}_{14} \mathrm{~B}$ are shown at the bottom of the plot. (b) Results of thermal analysis of the as-spun $\operatorname{Pr}_{2} \mathrm{Co}_{14} \mathrm{~B}$ ribbons showing simultaneously collected DSC on the right axis and TG on the left axis. A small magnetic field gradient was imposed on the sample during the measurements. (c) Processing thermal profiles showing measured sample temperature vs processing time.

To corroborate these general interpretations of the x-ray diffraction data from the surface of the ribbons transmission electron microscopy analysis of the internal portions of the samples was performed. Key results are summarized in Figure 3. In this figure, TEM images and associated electron diffraction patterns are shown for the four samples for which the XRD data are shown in Figure 2c,d. These samples exemplify the effects inferred from XRD on crystallinity and phase selection. At both processing temperatures, 450 and $650^{\circ} \mathrm{C}$, the difference in crystallite size between samples annealed in zero field and at $\mathrm{H}=90 \mathrm{kOe}$ is immediately apparent. Figure 3a shows crystallite sizes from tens of nm up to $100-200 \mathrm{~nm}$
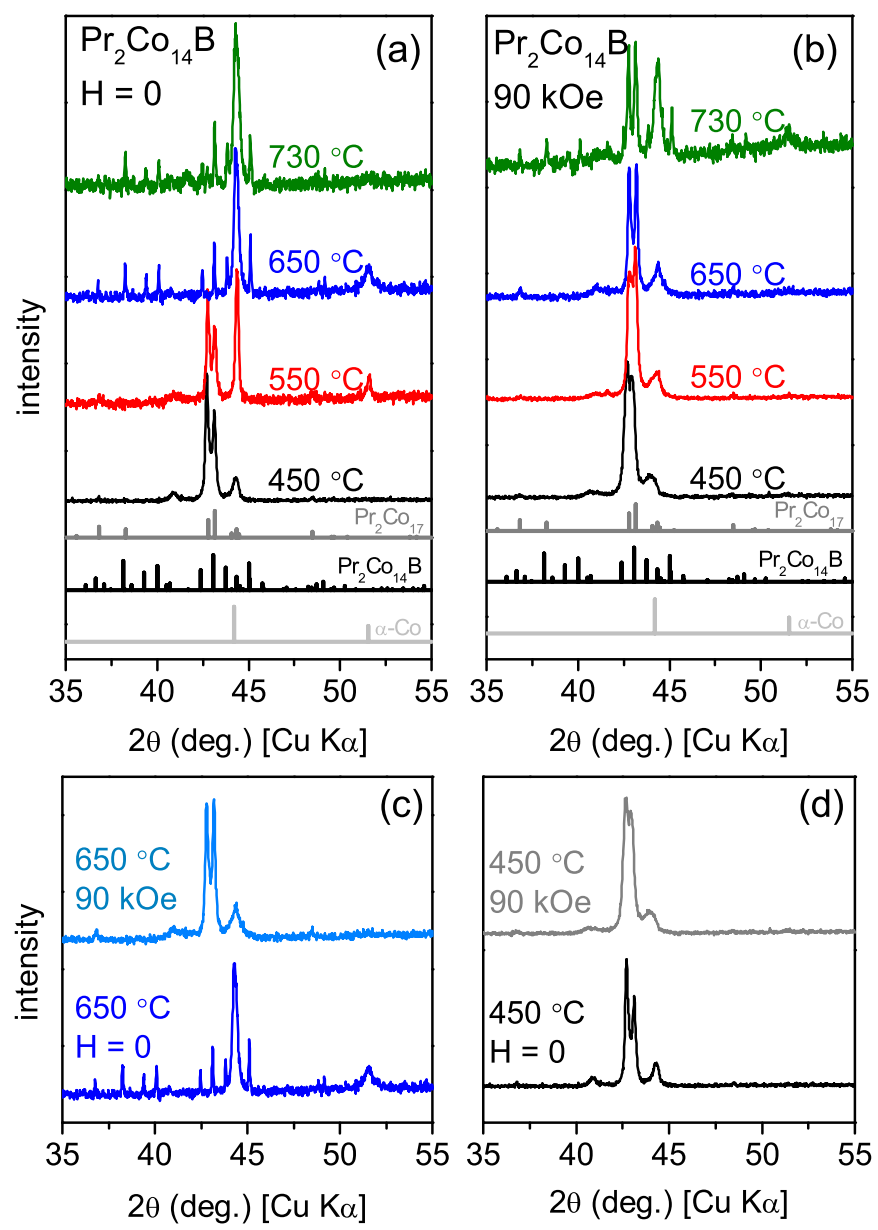

FIG. 2. (a) X-ray diffraction patterns after heating to the indicated temperatures in zero field. (b) X-ray diffraction patterns after heating to the indicated temperatures in a $90 \mathrm{kOe}$ magnetic field. (c) Comparison of samples heated to $650^{\circ} \mathrm{C}$ in zero and $90 \mathrm{kOe}$ fields. (d) Comparison of samples processed at $450^{\circ} \mathrm{C}$ in zero and $90 \mathrm{kOe}$ fields.

at $450^{\circ} \mathrm{C}$ in zero field. Figure $3 \mathrm{~b}$ shows significantly smaller grain sizes, only up to about $50 \mathrm{~nm}$, as well as an amorphous component indicated by the diffuse ring in the diffraction pattern. Comparison of the samples heated at $650^{\circ} \mathrm{C}$ (Figures $3 \mathrm{c}$ and 3d) shows that the particle size effect persists to this temperature as well. Estimated particle sizes range from 50 to 300 $\mathrm{nm}$ for $650^{\circ}$ and $\mathrm{H}=0$ and are limited to less than about 100 $\mathrm{nm}$ for $650^{\circ}$ and $\mathrm{H}=90 \mathrm{kOe}$. Energy dispersive spectroscopy identified some elemental Co grains in the $650^{\circ} \mathrm{C}$-zero field sample but not in the $650^{\circ} \mathrm{C}-90 \mathrm{kOe}$ sample, in qualitative agreement with the XRD results. Distinguishing $\mathrm{Pr}_{2} \mathrm{Co}_{17}$ and $\operatorname{Pr}_{2} \mathrm{Co}_{14} \mathrm{~B}$ by this technique is difficult due to their similar $\mathrm{Pr} / \mathrm{Co}$ ratios, 0.12 and 0.14 , respectively.

The present study was designed to investigate effects of high magnetic fields during the microstructural development of a rare-earth magnet alloy, rather than to develop optimized permanent magnet properties. However, the magnetic behavior of the samples after processing can provide some insight 

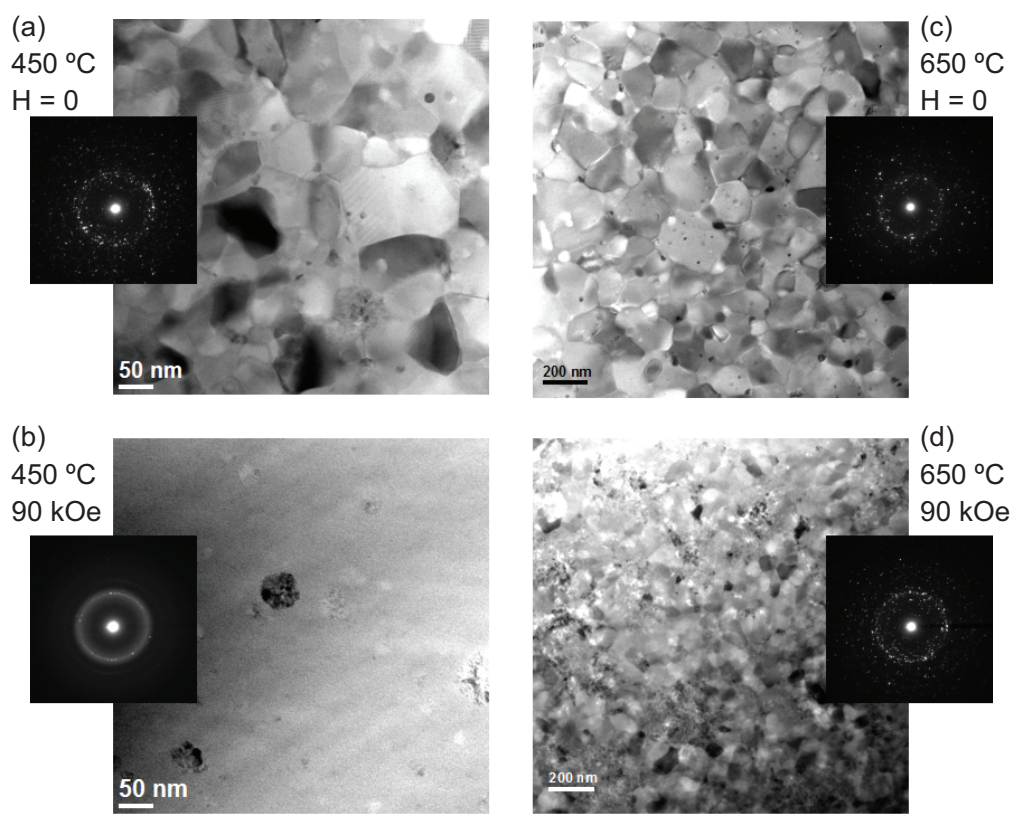

FIG. 3. TEM images and electron diffraction patterns from $\operatorname{Pr}_{2} \mathrm{Co}_{14} \mathrm{~B}$ ribbons after heating to the indicated temperatures in the indicated magnetic fields. Note the different scale bars between images for the $450^{\circ} \mathrm{C}$ samples $(\mathrm{a}, \mathrm{b})$ and the $650^{\circ} \mathrm{C}$ samples $(\mathrm{c}, \mathrm{d})$.

into the microstructure as well. Magnetization loops between 30 and $-30 \mathrm{kOe}$ were measured at room temperature and the results are summarized in Table I for samples heated to 450 and $650^{\circ} \mathrm{C}$. The most apparent trend is that for a fixed processing temperature samples processed at $90 \mathrm{kOe}$ have higher magnetization measured at $30 \mathrm{kOe}\left(\mathrm{M}_{30 \mathrm{kOe}}\right)$ and lower intrinsic coercivity $\left(\mathrm{H}_{\mathrm{Ci}}\right)$. This observation is consistent with the conclusion drawn above that the magnetic field favors $\mathrm{Pr}_{2} \mathrm{Co}_{17}$ over $\mathrm{Pr}_{2} \mathrm{Co}_{14} \mathrm{~B} . \mathrm{Pr}_{2} \mathrm{Co}_{17}$ is an easy-plane ferromagnet [26], while $\mathrm{Pr}_{2} \mathrm{Co}_{14} \mathrm{~B}$ is an easy axis and high anisotropy ferromagnet [17]. Thus, it may be expected that an increased $\mathrm{Pr}_{2} \mathrm{Co}_{17}$ content would correspond to lower coercivity, as observed. The coercivity is also expected to be affected by the grain size, but the low intrinsic contribution to coercivity from the easy-plane magnetic phase $\mathrm{Pr}_{2} \mathrm{Co}_{17}$ dominates the extrinsic microstructural contribution. The higher magnetization measured at $30 \mathrm{kOe}$ for the samples processed at $90 \mathrm{kOe}$ can also be attributed to the chemical phase selection. The saturation moment per unit mass is higher for than $\mathrm{Pr}_{2} \mathrm{Co}_{17}$ $(155 \mathrm{emu} / \mathrm{g}[26,27])$ than for $\mathrm{Pr}_{2} \mathrm{Co}_{14} \mathrm{~B}$ (125 emu/g [17]). In addition, the hard ferromagnetic phase $\mathrm{Pr}_{2} \mathrm{Co}_{14} \mathrm{~B}$ with an anisotropy field near $100 \mathrm{kOe}$ [17], will not be near saturation at $30 \mathrm{kOe}$, while $\mathrm{Pr}_{2} \mathrm{Co}_{17}$ with an anisotropy field of about 30 kOe [26], should be nearly saturated at this field.

\section{SUMMARY}

Large magnetic fields applied during thermal processing significantly alter the microstructural evolution of $\mathrm{Pr}_{2} \mathrm{Co}_{14} \mathrm{~B}$ alloys. Crystallite sizes were reduced in samples processed in an applied field of $90 \mathrm{kOe}$ compared to those processed
TABLE I. Results of magnetization loops for applied fields between 30 and $-30 \mathrm{kOe}$ measured at $300 \mathrm{~K}$.

\begin{tabular}{ccccc}
\hline \hline \multicolumn{2}{c}{ processing parameters } & \multicolumn{3}{c}{ magnetic properties } \\
$\mathrm{T}$ & $\mathrm{H}$ & $\mathrm{H}_{\mathrm{Ci}}$ & $\mathrm{M}_{\mathrm{R}}$ & $\mathrm{M}_{30 \mathrm{kOe}}$ \\
${ }^{\circ} \mathrm{C}$ & $\mathrm{kOe}$ & $\mathrm{kOe}$ & $\mathrm{emu} / \mathrm{g}$ & $\mathrm{emu} / \mathrm{g}$ \\
\hline 450 & 0 & 6.5 & 36.7 & 66.9 \\
450 & 90 & 1.2 & 28.1 & 105.5 \\
650 & 0 & 7.5 & 40.5 & 62.5 \\
650 & 90 & 2.8 & 33.7 & 87.9 \\
\hline \hline
\end{tabular}

in zero field at the same temperature, and the magnetic field suppresses the formation of both $\alpha$-Co and $\operatorname{Pr}_{2} \mathrm{Co}_{14} \mathrm{~B}$, either through thermodynamic stabilization of $\mathrm{Pr}_{2} \mathrm{Co}_{17}$ or through slowing the kinetics of the crystallization and phase transformations. Although effects of the magnetic field are in this case detrimental to the magnetic properties due to the preference for the easy plane ferromagnet $\mathrm{Pr}_{2} \mathrm{Co}_{17}$, this work does demonstrate that increased microstructural control can be achieved by including a strong magnetic field as a processing parameter. These observations motivate further study to understand the effects of the field and to develop thermomagnetic processing strategies that may produce enhanced permanent magnet performance.

\section{ACKNOWLEDGEMENTS}

This work is supported by the Critical Materials Institute, an Energy Innovation Hub funded by the U.S. Department of Energy, Office of Energy Efficiency and Renewable Energy, 
Advanced Manufacturing Office.

[1] D. Brown, B.-M. Ma, and Z. Chen, J. Magn. Magn. Mater. 248, 432 (2002).

[2] J. W. Cahn, J. Appl. Phys. 34, 3581 (1963).

[3] K. J. D. Vos, Magnetism and Metallurgy 1, 473 (1969).

[4] R. R. Heikes, Phys. Rev. 2, 446 (1955).

[5] Y. Liu, J. Zhang, S. Cao, X. Zhang, G. Jia, Z. Ren, X. Li, C. Jing, and K. Deng, Phys. Rev. B 72, 214410 (2005).

[6] T. Onogi, K. Koyama, and K. Watanabe, Journal of the Japan Institute of Metals 71, 489 (2007).

[7] Y. Li, O. Rios, and M. R. Kessler, Appl. Mater. Interfaces 6, 19456 (2014).

[8] S. Rivoirard, JOM 65, 901 (2013).

[9] C. Wang, Y. S. Lai, C. C. Hsieh, W. C. Chang, H. W. Chang, and A. C. Sun, J. Appl. Phys. 109, 07A715 (2011).

[10] Y. K. Zhang, J. Gao, H. Yasuda, D. M. Herlach, and J. C. He, J. Alloys Compd. 493, L8 (2010).

[11] P. Courtois, R. P. de la Bâthie, and R. Tournier, J. Magn. Magn. Mater. 153, 224 (1996).

[12] B. Z. Cui, C. T. Yu, K. Han, J. P. Liu, H. Garmestani, M. J. Pechan, and H. J. Schneider-Muntau, J. Appl. Phys. 97, 10F308 (2005).

[13] H. Kato, T. Miyazaki, M. Sagawa, and K. Koyama, Appl. Phys. Lett. 84, 4230 (2005).

[14] S. Liesert, D. Fruchart, P. de Rango, S. Rivoirard, J. L. Soubeyroux, R. P. de la Bâithe, and R. Tournier, J. Alloys Compd. 262-263, 366 (1997).

[15] H. Kato, K. Koyama, and K. Takahashi, J. Appl. Phys. 109, 07 A726 (2011).

[16] K. H. J. Buschow, D. B. de Mooji, S. Sinnema, R. J. Radwanski, and J. J. M. Franse, J. Magn. Magn. Mater. 51, 211 (1985).

[17] R. Grössinger, R. Krewenka, H. R. Kirchmayr, S. Sinnema, Y. Fu-Ming, H. Ying-Kai, and F. R. DeBoer, J. Less-Common Met. 132, 265 (1987).

[18] C. D. Fuerst, J. F. Herbst, and F. E. Pinkerton, J. Appl. Phys. 64, 5556 (1988).

[19] C. N. Christodoulou, T. B. Massalski, and W. E. Wallace, J. Magn. Magn. Mater. 125, 177 (1993).

[20] L. Withanawasam, I. Panagiotopoulos, and G. C. Hadjipanayis, J. Appl. Phys. 79, 4837 (1996).

[21] H. Ucar, I. C. Nlebedim, M. P. Paranthaman, and R. W. McCallum, J. Appl. Phys. 116, 233901 (2014).

[22] Y. Otani, H. Sun, and J. M. D. Coey, J. Appl. Phys. 67, 4616 (1990).

[23] G. Ludtka, "Magnetic field processing - a heat free heat treating method," http://info.ornl.gov/sites/publications/files/Pub35015.pdf (2012).

[24] Y. Chen, J. Liang, X. Chen, and Q. Liu, J. Alloys Compd. 289, 96 (1999).

[25] C. N. Christodoulou, T. B. Massalski, and W. E. Wallace, J. Phase Equilib. 14, 31 (1993).

[26] X.-F. Han, H.-M. Jin, Z.-J. Wang, T. S. Zhao, and C. C. Sun, Phys. Rev. B 47, 3248 (1993).

[27] K. Inomata, J. Phys. Soc. Japan 41, 1890 (1976). 